\title{
Anti-Obesity and Anti-Diabetic Effects of Ishige okamurae
}

\author{
Hye-Won Yang, K.H.N. Fernando, Jae-Young Oh, Xining Li, You-Jin Jeon * and BoMi Ryu *D
}

Department of Marine Life Science, Jeju National University, Jeju 63243, Korea; koty221@naver.com (H.-W.Y.); hiruninfdo@gmail.com (K.H.N.F.); ojy0724@naver.com (J.-Y.O.); xiningmarinesci666@naver.com (X.L.)

* Correspondence: youjin2014@gmail.com (Y-J.Y.); ryu.bomi@gmail.com (B.R.); Tel.: +82-64-754-3475 (B.R.)

Received: 15 March 2019; Accepted: 25 March 2019; Published: 29 March 2019

\begin{abstract}
Obesity is associated with several health complications and can lead to the development of metabolic syndrome. Some of its deleterious consequences are related to insulin resistance, which adversely affects blood glucose regulation. At present, there is a growing concern regarding healthy food consumption, owing to awareness about obesity. Seaweeds are well-known for their nutritional benefits. The brown alga Ishige okamurae (IO) has been studied as a dietary supplement and exhibits various biological activities in vitro and in vivo. The bioactive compounds isolated from IO extract are known to possess anti-obesity and anti-diabetic properties, elicited via the regulation of lipid metabolism and glucose homeostasis. This review focuses on IO extract and its bioactive compounds that exhibit therapeutic effects through several cellular mechanisms in obesity and diabetes. The information discussed in the present review may provide evidence to develop nutraceuticals from IO.
\end{abstract}

Keywords: Ishige okamurae; marine alga; obesity; diabetes; nutraceuticals

\section{Introduction}

Over the past 50 years, obesity has become a global public health issue that negatively affects quality of life and increases the risk of various illnesses and healthcare costs worldwide [1-3]. Obesity is considered a risk factor for coronary artery diseases, cerebrovascular accidents, type-2 diabetes mellitus, systemic hypertension, various cancers, fatty liver disease, osteoarthritis, and gynecological disorders [4]. An understanding of the molecular basis of obesity-associated diseases is required to approach its prevention. The properties of adipose tissue and adipocytes in obesity have been studied [5], and Higdon and Frei [6] also emphasized that obesity is a chronic oxidative stress condition due to an imbalance among tissue active oxygen, reactive oxygen species (ROS) and antioxidants.

Oxidative stress also plays a key role in the pathogenesis of many other progressive diseases including diabetes, atherosclerosis and cancer [7-9]. In addition, lipid accumulation has been correlated with various markers of systemic oxidative stress [10]. Furukawa et al. [11] reported that oxidative stress mediates the obesity-associated development of metabolic syndrome via two mechanisms: (1) increased oxidative stress due to lipid accumulation leads to dysregulated production of adipocytokines, and (2) selective increase in ROS production due to lipid accumulation leads to elevation in systemic oxidative stress. Oxidative stress can activate a series of stress pathways involving a family of serine/threonine kinases, resulting in a negative effect on insulin signaling [12], and an increase in the production of free radicals or impaired antioxidant defenses. Diabetes is characterized by hyperglycemia and insufficiency in the secretion or action of endogenous insulin [13]. An increase in oxidative stress can lead to hyperglycemia in both type-1 and type-2 diabetes [14,15]. Tan et al. [16] showed that hydrogen peroxide $\left(\mathrm{H}_{2} \mathrm{O}_{2}\right)$ stimulated the inhibition of insulin-induced glucose uptake 
in vitro. In that study, oxidative stress directly causes insulin resistance via overactivation of extracellular signal-related kinase (ERK).

Current available therapies for obesity and diabetes have either limited efficacy or cause side effects. Therefore, many studies have suggested that natural sources can be used as complementary treatments and preventive materials with less toxic and fewer side effects [17]. Marine algae have been identified as rich sources of structurally diverse bioactive compounds including pigments, fucoidans, phycocolloids, and phlorotannis, with nutraceutical and biomedical potential $[18,19]$. Ishige okamurae (IO) is an edible brown seaweed found in temperate coastal areas, such as the Korean peninsula [20]. It is abundant along the coast of Jeju Island and is a potential functional food. In this review, we discuss the anti-obesity and anti-diabetic effects of IO extract and its cellular mechanisms of action. We also suggest its use as a potential nutraceutical source.

\section{Anti-Obesity and Anti-Diabetic Properties of IO Extract}

Ishige is a genus of brown algae with two species-Ishige foliacea and IO. Studies on the extracts of Ishige, including Ishige foliacea and IO, have reported various in vitro and in vivo activities, such as antioxidant, anti-diabetic, and anti-obesogenic effects [21-23]. Owing to these bioactivities, these extracts have been gaining increased attention in recent years for potential nutraceutical application in metabolic syndrome.

Metabolic syndrome is characterized by an increase in ROS levels, which cannot be counteracted by endogenous antioxidant systems [24]. The increase in ROS levels plays a key role in the development of metabolic diseases, which could lead to changes in glucose uptake, exacerbating diabetes mellitus, obesity, cardiovascular diseases, or cancer $[24,25]$. The antioxidant properties of Ishige foliacea and IO methanol extracts have been investigated in terms of their free-radical which includes 1,1-diphenyl-2-picryl hydrazyl (DPPH); 2,2-azobis(3-ethylbenzothiazoline-6-sulfonate (ABTS) and nitrite scavenging activity [21]. Furthermore, Heo and Jeon [26] reported that IO enzymatically extracted with different carbohydrases and proteases exhibits antioxidative effects. In particular, Ultraflo extract, which is a carbohydrase-based enzymatic extract, can scavenge free radicals, and Kojizyme extract, which is a protease-based extract, can reduce the DNA damage caused by hydrogen peroxide $\left(\mathrm{H}_{2} \mathrm{O}_{2}\right)$. Thus, the antioxidant efficacy of IO extracts indicates that it is a potential functional food, which can be used as a supplement for patients with metabolic syndrome.

Diabetes and obesity are common, closely interrelated disorders and are caused by poor metabolic conditions. Obesity, a characteristic feature of metabolic syndrome, involves the accumulation of abnormal or excessive fat that may interfere with the maintenance of an optimal state of health [27]. It is also associated with a systemic increase in oxidative stress, resulting in adipokine imbalance [28]. Previous in vitro and in vivo studies have suggested that oxidative stress can cause obesity through increased proliferation of pre-adipocytes and increased size of differentiated adipocytes [29,30].

Cha and Cheon [31] showed that IO extract can inhibit lipid accumulation induced during adipogenesis of 3T3-L1 preadipocytes. The concerted regulation of gene expression by various adipogenic factors is required for the differentiation of preadipocytes to adipocytes. Furthermore, research on the mechanism underlying preadipocyte mitogenesis and differentiation into adipocytes may help understand the initiation and progression of obesity and its associated diseases. Peroxisome proliferator-activated receptors (PPAR $\gamma$ ) has been studied for its involvement in the regulation of nutrient sensing and glucose and lipid metabolism [32]. Expression level of PPAR $\gamma$ is highest in adipose tissue [33] when it regulates the transcriptional cascade involved in adipocyte differentiation [34]. The hormone nuclear receptor PPAR $\gamma$ plays an important role in the regulation of downstream adipogenic genes [33]. Expression levels of PPAR $\gamma$ mRNA were significantly decreased by the IO extract during 10 days of induction [31]. Thus, the antioxidant effect of IO extract can inhibit the accumulation of lipids and modulate PPAR $\gamma$ expression. Although IO extract can decrease the levels of PPAR $\gamma$, previous studies showed the effect of IO extract against obesity through other adipogenic transcription factors. The IO extract can suppress the increase in lipid droplet size by reducing the 
expression of adipogenic transcription factors in white adipose tissue (WAT), which is larger in a high-fat diet (HFD)-fed mice than in mice on a normal diet $[35,36]$. Therefore, IO extract can reduce body weight gain by preventing an increase in WAT mass and ameliorating HFD-induced obesity.

Adipose tissue helps maintain glucose and lipid homeostasis through the secretion of various factors and through neural networks [37-39]. Diabetes in obese people occurs mostly due to insulin resistance and subsequent hyperinsulinemia through adipogenesis and the insulin signaling pathway. In addition, oxidative stress has been linked with disruption of insulin secretion by pancreatic $\beta$-cells [40], glucose transport in muscle [8], and adipocytokines [41].

A widely used preclinical model of diabetes is $d b / d b$ mice, characterized by hyperglycemia, hyperinsulinemia, hyperleptinemia, and obesity, similar to type-2 diabetes [42]. C57BL/KsJ- $d b / d b$ mice were fed a standard semi-synthetic diet (AIN-93G) with IO extract $(0.5 \%, \mathrm{w} / \mathrm{w}$; IO extract supplementation), resulting in downregulated fasting blood glucose levels. IO extract supplementation controlled blood glucose levels during the intraperitoneal glucose tolerance test (IPGTT) [22]. Homeostatic model assessment (HOMA) is a method for assessing insulin resistance (IR) and is a useful index of insulin sensitivity [43]. It has been shown that HOMA-IR is lowered following IO extract supplementation [22]. Previous studies have suggested that therapeutic agents may be required to prevent hyperglycemic conditions in patients with early-stage type-2 diabetes. IO extract supplementation significantly lowered glycated hemoglobin (HbA1c) levels [22], which is useful for monitoring glycemic control in diabetic patients [44]. Taken together, IO extract supplementation can control blood glucose levels and improve insulin resistance in $d b / d b$ mice. We suggest that IO extract can be used as an antidiabetic supplement.

\section{Composition of IO}

Many brown algae species are used as food ingredients and supplements and possess a variety of biological activities. These biological activities are related to the presence of polyphenols, polysaccharides and pigments. Among polyphenols, one of the most common classes of secondary metabolites derived from polymerized phloroglucinol units are phlorotannins [45]. Phlorotannins are tannin derivatives composed of several phloroglucinol units isolated from brown algae [19]. It has been reported that brown algae are richer in phlorotannins than other marine algae. Polyphenols can react with oxidants in one-electron reactions, pairing with the free electron of the oxidant to become chemically inactive. Therefore, polyphenols act as antioxidants that inhibit the formation of free radicals in biological systems [46]. In addition, previous studies have examined various biological activities associated with polyphenols from brown algae, including antioxidant, anti-coagulant, anti-bacterial, anti-inflammatory, and anti-cancer effects $[18,47,48]$. Thus, phlorotannins isolated from brown seaweeds represent the most widely studied class of secondary metabolites in marine organisms, with potential use in the nutraceutical and functional food industry.

Yoon et al. [49] studied the secondary metabolites of IO extract with antioxidant effects, including phloroglucinol, 6,6'-bieckol, and diphlorethohydroxycarmalol (DPHC). Octaphlorethol A (OPA) was also isolated and purified from IO extract [50]. Recently, a novel polyphenol-compound, ishophloroglucin A (IPA) with $\alpha$-glucosidase inhibitory activity was isolated from IO extract [51]. Zou et al. [52] evaluated the antioxidant effects of 6,6'-bieckol and DPHC by using the electron spin resonance (ESR) technique. The two phlorotannins displayed potent radical scavenging activities against DPPH as well as hydroxyl, alkyl, and superoxide radicals. Moreover, effective concentration $\left(\mathrm{EC}_{50}\right)$ values of phlorotannins, defined as the concentration at which the radicals were scavenged by $50 \%$, are summarized in Table 1 . Heo and Jeon [53] reported the cytoprotective effect of DPHC in Vero cells against oxidative stress induced by hydrogen peroxide $\left(\mathrm{H}_{2} \mathrm{O}_{2}\right)$. 
Table 1. $\mathrm{EC}_{50}$ values of phlorotannins from Ishige okamurae.

\begin{tabular}{ccccc}
\hline & \multicolumn{4}{c}{ EC $_{\mathbf{5 0}}(\boldsymbol{\mu M} \pm \mathbf{S D})$} \\
\cline { 2 - 5 } & DPPH & Hydroxyl & Alkyl & Superoxide \\
\hline 6,6'-bieckol & $9.1 \pm 0.4$ & $23.7 \pm 1.1$ & $17.3 \pm 1.0$ & $15.4 \pm 0.9$ \\
Diphlorethohydroxycarmalol (DPHC) & $10.5 \pm 0.5$ & $27.1 \pm 0.9$ & $18.8 \pm 1.2$ & $16.7 \pm 0.6$ \\
Phloroglucinol & Not determined & $408.5 \pm 3.7$ & $103.5 \pm 1.9$ & $124.7 \pm 2.4$ \\
\hline
\end{tabular}

Several studies have reported that among the pigments of brown algae, fucoxanthin can reduce oxidative stress and symptoms of metabolic syndrome via its anti-diabetic and anti-obesogenic effects [54-57]. In addition, Kang et al. [58] reported that fucoxanthin isolated from IO can reduce high glucose-induced oxidative stress in human umbilical vein endothelial cells (HUVEC) and in zebrafish models. Taken together, the antioxidative effects of IO may be effective as supplementary treatment of metabolic syndrome, including obesity and diabetes.

\subsection{Anti-Obesity Effect of IO}

When caloric expenditure is lower than caloric intake, adipocytes play a critical role by storing triacylglycerol and regulating metabolism in obesity. In fat tissue, adipocyte differentiation and lipid accumulation occur through adipocyte-specific proteins including enhancer binding protein (C/EBP), sterol-regulatory element-binding protein 1c (SREBP-1c), peroxisome proliferator activated receptor- $\gamma($ PPAR $\gamma)$, adiponectin, perilipin, fatty acid synthase (FAS), fatty acid binding protein (FABP4), and leptin [59]. According to Cha and Cheon [31], IO extract is known to inhibit lipid accumulation, which is induced during adipogenesis from 3T3-L1 preadipocytes. Previous studies have focused on the inhibition of lipid accumulation in 3T3-L1 cells through decreased expression levels of adipogenic-specific factors by polyphenols such as dieckol [60], epigallocatechin-3-gallate [61], and resveratrol [62]. Several studies have found that IO extract inhibited fat accumulation in 3T3-L1 cells through a molecular mechanism involving adipocyte-specific proteins.

DPHC from IO extract has potential antiadipogenic effects elicited via the inhibition of adipocyte differentiation and adipogenesis. Kang et al. [63] reported that levels of the adipogenesis-specific proteins including C/EBP $\alpha$, SREBP-1c, PPAR $\gamma$, and adiponectin were decreased to activate molecular mechanisms involved in 3T3-L1 adipocyte differentiation. These transcription factors are highly expressed in adipocytes and are involved in the mediation of lipid synthesis, lipolysis, and glucose uptake in adipocytes. DPHC can disrupt fatty acid synthesis by downregulating adipocyte-specific proteins including perilipin, FAS, FABP4, and leptin. Furthermore, DPHC can activate adenosine monophosphate-activated protein kinase (AMPK) and acetyl-CoA carboxylase (ACC), resulting in the inhibition of lipogenesis, adipocyte differentiation, and fatty acid synthesis in adipocytes. Besides the increase in AMPK and ACC, preadipocyte apoptosis also has an anti-obesity effect. Park et al. [64] reported that DPHC induced apoptosis in 3T3-L1 preadipocytes through the intrinsic pathway by regulating the protein levels of Fas, Bax, Bcl-2, caspase-9, caspase-3, and PARP. Taken together, DPHC can be used as a potential therapeutic agent against obesity.

\subsection{Anti-Diabetic Activity of IO}

Diabetes, a serious chronic metabolic disease, may develop with obesity and ageing in the general population. In addition, rapidly increasing blood glucose levels are a result of the hydrolysis of starch by pancreatic $\alpha$-amylase and glucose uptake by intestinal $\alpha$-glucosidases. These enzymes play a crucial role in the effective regulation of glucose absorption [65]. Therefore, an important strategy for suppressing postprandial hyperglycemia is the inhibition of $\alpha$-amylase and $\alpha$-glucosidase activities $[66,67]$. A previous study with C57BL/KsJ- $d b / d b$ mice showed that IO extract supplementation prevented insulin resistance and regulated blood glucose levels in hyperglycemia [22]. 
Lee and Jeon [19] focused on developing potential anti-diabetic nutraceutical and functional foods from phlorotannins.

Furthermore, several studies found that IO extract showed anti-diabetic activity by inhibiting $\alpha$-amylase and $\alpha$-glucosidases. Phlorotannins isolated from IO extract have excellent anti-diabetic properties. DPHC $\left(\mathrm{IC}_{50}=0.53 \pm 0.08\right.$ and $\left.0.16 \pm 0.01 \mathrm{mM}\right)$ showed effective inhibitory effects against $\alpha$-amylase and $\alpha$-glucosidase compared to acarbose $\left(\mathrm{IC}_{50}=1.10 \pm 0.07\right.$ and $\left.1.05 \pm 0.03 \mathrm{mM}\right)$, which was used as the positive control [68]. DPHC significantly suppressed the increase in postprandial blood glucose levels in both streptozotocin-induced diabetic and normal mice after the consumption of starch [68]. Moreover, Lee et al. [69] described that DPHC treatment protected high glucose-induced damage in RINm5F pancreatic $\beta$-cells. The dysfunction of pancreatic $\beta$-cells has a central role in the pathogenesis of type- 2 diabetes [70]. Therefore, DPHC can delay the absorption of dietary carbohydrates and improve secretory responsiveness of insulin following stimulation with glucose.

Recently, IPA, a novel polyphenol-compound derived from IO extract showed a solid $\alpha$-glucosidase inhibitory activity [51]. The study showed the application of IPA in standardizing the inhibition of $\alpha$-glucosidase activity of IO extract and proposed IPA potential in the application of marine-derived nutraceuticals.

\section{Potential Nutraceutical Use of IO}

The role of food is to provide enough nutrients to meet metabolic requirements, which is relevant to well-being, good health, and disease management [71]. Recently, consumer awareness of bioactive compounds as functional ingredients has increased, and knowledge about their various health benefits is increasing. Seaweeds are rich sources of structurally diverse bioactive compounds with valuable nutraceutical, pharmaceutical and cosmeceutical potentials [72]. Antioxidant properties of seaweeds enable their use as nutraceuticals and functional food ingredients [73]. A considerable number of bioactive compounds has been isolated from seaweeds and evaluated for their potential as functional food ingredients to assist in the treatment of metabolic diseases such as cancer, hypertension and diabetes [73].

IO is an edible brown seaweed that grows on rocks in the upper and middle intertidal zones in the northwest Pacific Ocean (Korea, Japan, and China), where it forms continuous bands [20]. As shown in Table 2, previous studies have discussed the usefulness of bioactive compounds from IO as functional ingredients $[49,58,74]$. Additionally, the antioxidant properties of the methanol extract and enzymatic extract from IO were evaluated to develop potential functional food materials against oxidative stress [21,26]. IO extract is rich in secondary metabolites such as phlorotannins, carotenoids, and polysaccharides with various bioactive properties.

Table 2. Bioactivities of functional ingredients from Ishige okamurae.

\begin{tabular}{ccc}
\hline Functional Ingredient & Bioactivities & References \\
\hline Methanolic extract & Antioxidant, anti-MMP, and anti-diabetic & {$[21,22,74]$} \\
Ethanolic extract & Anti-inflammatory & {$[75]$} \\
Enzymatic extract & Antioxidant & {$[26]$} \\
Fermented extract & Radioprotective and antioxidant & {$[76]$} \\
$6,6^{\prime}$-Bieckol & Cholinesterase inhibition & {$[49]$} \\
Diphlorethohydroxycarmalol & Antioxidant, anti-cancer, anti-HIV, & {$[52,53,64,68,69,77-79]$} \\
(DPHC) & anti-obesity, and anti-diabetic & {$[58,80]$} \\
Fucoxanthin & Antioxidant, anti-inflammatory & {$[20]$} \\
Ishigoside & Antioxidant & {$[51]$} \\
Ishophloroglucin A (IPA) & - -glucosidases inhibition & {$[49]$} \\
Phloroglucinol & Cholinesterase inhibition & \\
\hline
\end{tabular}

$6,6^{\prime}$-bieckol is another phlorotannin from IO which possesses in vitro and in vivo neuroprotective effects. 6,6'-bieckol suppresses acetylcholinesterase (AChE) activity with an $\mathrm{IC}_{50}$ value of 
$46.42 \pm 1.19 \mu \mathrm{M}[49]$. AChE plays a key role in the regulation of several physiological reactions by hydrolyzing the neurotransmitter acetylcholine in the cholinergic synapses [81,82]. In addition, Alzheimer's disease (AD) is related to a deficit in cholinergic functions in the brain [83]. Thus, the application of 6,6'-bieckol as an alternative for AChE inhibitors suggests a therapeutic potential in AD. Fucoxanthin, an accessory pigment in chloroplasts, is a well-known brown seaweed carotenoid with numerous important bioactive properties [84]. It is also one of the major constituents of IO. Kim et al. [80] showed that fucoxanthin from IO reduced the production of nitric oxide (NO) and inflammatory mediators, including inducible nitric oxide synthase (iNOS) and cyclooxygenase-2 (COX-2), and inhibited nuclear factor (NF)- $\mathrm{KB}$ activation and mitogen-activated protein kinases (MAPKs; JNK, ERK and p38) signal pathways in LPS-stimulated RAW264.7. In LPS-treated macrophages, pro-inflammatory cytokines and gene expression were upregulated through NF- $\mathrm{KB}$ activation and MAPK signaling pathways $[85,86]$. Cancer is characterized by uncontrolled cell growth and spread [87]. Fucoxanthin has the potential to inhibit the proliferation of melanoma cell lines (B16F10 cells) through cell cycle arrest during the G0/G1 phase and the apoptotic pathway [64]. Fucoxanthin also decreases Bcl-xL expression level, which is a critical regulator of the apoptotic pathway. Moreover, it has been shown that fucoxanthin suppressed in vivo growth of B16F10 melanoma in Balb/c mice. Therefore, researchers have been interested in identifying new anti-cancer drugs from marine sources, which supposedly have fewer adverse side effects unlike synthetic drugs [88].

\section{Conclusions}

Obesity is associated with lipid accumulation together with oxidative stress, which increases insulin resistance and eventually results in diabetes. In this review, we have discussed the antioxidant properties of IO extract and the mechanisms of action underpinning its anti-obesity and anti-diabetic effects (Figure 1).

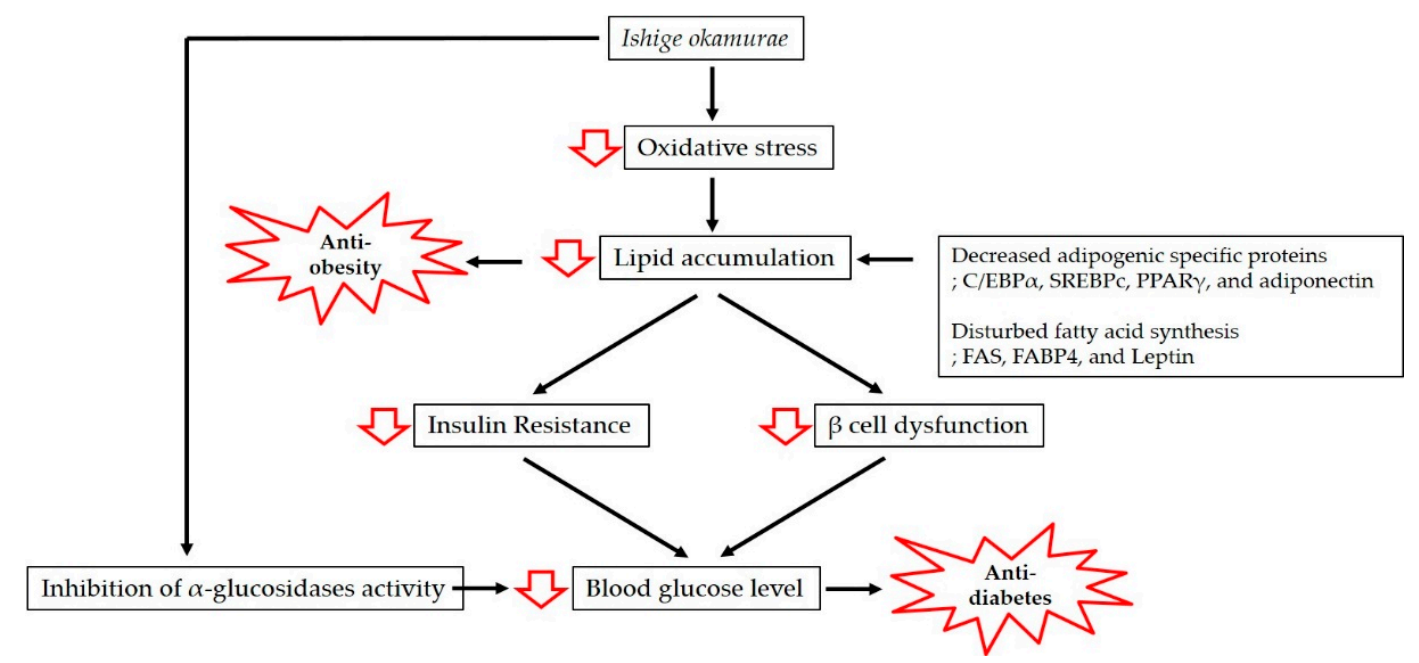

Figure 1. Mechanisms involved in the anti-obesity and anti-diabetic effects of Ishige okamurae.

The significant health benefits associated with IO may represent an interesting progress in the search for novel functional applications. IO can also be used as a therapeutic agent and functional food against metabolic syndrome.

Author Contributions: H.-W.Y.: Collection and assembly of data, manuscript writing; K.H.N.F., J.-Y.O., X.L.: Collection and assembly of data and addition of valuable comments; Y.-J.J.: final approval of manuscript; B.R.: Conception and design, data analysis and interpretation, final approval of manuscript. All the authors read and approved the final version of the manuscript.

Funding: This research was a part of the project titled 'Development of functional food products with natural materials derived from marine resources', funded by the Ministry of Oceans and Fisheries, Korea. 
Conflicts of Interest: The authors declare no conflict of interest

\section{References}

1. World Health Organization. World Health Organization Obesity and Overweight Fact Sheet. 2016. Available online: https://www.who.int/news-room/fact-sheets/detail/obesity-and-overweight (accessed on 29 March 2019).

2. Scully, T. Society at large: The increasing prevalence of obesity is a worldwide phenomenon, affecting peoples from diverse cultural and economic backgrounds. Nature 2014, 508, S50. [CrossRef]

3. Ng, M.; Fleming, T.; Robinson, M.; Thomson, B.; Graetz, N.; Margono, C.; Mullany, E.C.; Biryukov, S.; Abbafati, C.; Abera, S.F. Global, regional, and national prevalence of overweight and obesity in children and adults during 1980-2013: A systematic analysis for the Global Burden of Disease Study 2013. Lancet 2014, 384, 766-781. [CrossRef]

4. Mozaffarian, D. Dietary and policy priorities for cardiovascular disease, diabetes, and obesity: A comprehensive review. Circulation 2016, 133, 187-225. [CrossRef]

5. Fernández-Sánchez, A.; Madrigal-Santillán, E.; Bautista, M.; Esquivel-Soto, J.; Morales-González, Á.; Esquivel-Chirino, C.; Durante-Montiel, I.; Sánchez-Rivera, G.; Valadez-Vega, C.; Morales-González, J.A. Inflammation, oxidative stress, and obesity. Int. J. Mol. Sci. 2011, 12, 3117-3132. [CrossRef]

6. Higdon, J.V.; Frei, B. Obesity and oxidative stress: A direct link to CVD? Am. Heart Assoc. 2003, 23, 365-367. [CrossRef]

7. Matsuda, M.; Shimomura, I. Increased oxidative stress in obesity: Implications for metabolic syndrome, diabetes, hypertension, dyslipidemia, atherosclerosis, and cancer. Obes. Res. Clin. Pr. 2013, 7, 330-341. [CrossRef]

8. Maddux, B.A.; See, W.; Lawrence, J.C.; Goldfine, A.L.; Goldfine, I.D.; Evans, J.L. Protection against oxidative stress-induced insulin resistance in rat L6 muscle cells by micromolar concentrations of $\alpha$-lipoic acid. Diabetes 2001, 50, 404-410. [CrossRef]

9. Nakazono, K.; Watanabe, N.; Matsuno, K.; Sasaki, J.; Sato, T.; Inoue, M. Does superoxide underlie the pathogenesis of hypertension? Proc. Natl. Acad. Sci. USA 1991, 88, 10045-10048. [CrossRef]

10. Keaney, J.F., Jr.; Larson, M.G.; Vasan, R.S.; Wilson, P.W.; Lipinska, I.; Corey, D.; Massaro, J.M.; Sutherland, P.; Vita, J.A.; Benjamin, E.J. Obesity and systemic oxidative stress: Clinical correlates of oxidative stress in the Framingham Study. Arterioscl. Throm. Vasc. 2003, 23, 434-439. [CrossRef] [PubMed]

11. Furukawa, S.; Fujita, T.; Shimabukuro, M.; Iwaki, M.; Yamada, Y.; Nakajima, Y.; Nakayama, O.; Makishima, M.; Matsuda, M.; Shimomura, I. Increased oxidative stress in obesity and its impact on metabolic syndrome. J. Clin. Investig. 2017, 114, 1752-1761. [CrossRef]

12. Rains, J.L.; Jain, S.K. Oxidative stress, insulin signaling, and diabetes. Free Radic. Biol. Med. 2011, 50, 567-575. [CrossRef]

13. Maritim, A.; Sanders, A.; Watkins Iii, J. Diabetes, oxidative stress, and antioxidants: A review. J. Biochem. Mol. Toxicol. 2003, 17, 24-38. [CrossRef]

14. Jain, S.K. Hyperglycemia can cause membrane lipid peroxidation and osmotic fragility in human red blood cells. J. Biol. Chem. 1989, 264, 21340-21345.

15. Jain, S.K.; Levine, S.N.; Duett, J.; Hollier, B. Elevated lipid peroxidation levels in red blood cells of streptozotocin-treated diabetic rats. Metabolism 1990, 39, 971-975. [CrossRef]

16. Tan, Y.; Ichikawa, T.; Li, J.; Si, Q.; Yang, H.; Chen, X.; Goldblatt, C.S.; Meyer, C.J.; Li, X.; Cai, L. Diabetic downregulation of Nrf2 activity via ERK contributes to oxidative stress-induced insulin resistance in cardiac cells in vitro and in vivo. Diabetes 2011, 60, 625-633. [CrossRef]

17. Chang, M.S.; Oh, M.S.; Jung, K.J.; Park, S.; Choi, S.B.; Ko, B.-S.; Park, S.K. Effects of Okchun-San, a herbal formulation, on blood glucose levels and body weight in a model of Type 2 diabetes. J. Ethnopharmacol. 2006, 103, 491-495. [CrossRef]

18. Heo, S.-J.; Kim, J.-P.; Jung, W.-K.; Lee, N.-H.; Kang, H.-S.; Jun, E.-M.; Park, S.-H.; Kang, S.-M.; Lee, Y.-J.; Park, P.-J. Identification of chemical structure and free radical scavenging activity of diphlorethohydroxycarmalol isolated from a brown alga, Ishige okamurae. J. Microbiol. Biotechnol. 2008, 18, 676-681. 
19. Lee, S.-H.; Jeon, Y.-J. Anti-diabetic effects of brown algae derived phlorotannins, marine polyphenols through diverse mechanisms. Fitoterapia 2013, 86, 129-136. [CrossRef]

20. Lee, K.M.; Boo, G.H.; Riosmena-Rodriguez, R.; Shin, J.A.; Boo, S.M. Classification of the genus Ishige (ishigeales, phaeophyceae) in the north Pacific Ocean with recognition of Ishige foliacea based on plastid rbcl and mitochondrial cox3 gene sequences 1. J. Phycol. 2009, 45, 906-913. [CrossRef]

21. Ahn, S.-M.; Hong, Y.-K.; Kwon, G.-S.; Sohn, H.-Y. Evaluation of antioxidant and nitrite scavenging activity of seaweed extracts. J. Life Sci. 2011, 21, 576-583. [CrossRef]

22. Min, K.-H.; Kim, H.-J.; Jeon, Y.-J.; Han, J.-S. Ishige okamurae ameliorates hyperglycemia and insulin resistance in C57BL/KsJ-db/db mice. Diabetes Res. Clin. Pr. 2011, 93, 70-76. [CrossRef] [PubMed]

23. Kang, M.-C.; Kang, N.; Ko, S.-C.; Kim, Y.-B.; Jeon, Y.-J. Anti-obesity effects of seaweeds of Jeju Island on the differentiation of 3T3-L1 preadipocytes and obese mice fed a high-fat diet. Food Chem. Toxicol. 2016, 90, 36-44. [CrossRef] [PubMed]

24. Casuso, R.A.; Huertas, J.R. Antioxidant Supplements in Obesity and Metabolic Syndrome: Angels or Demons. In Obesity; Elsevier: Amsterdam, The Netherlands, 2018; pp. 263-275.

25. Acin-Perez, R.; Enriquez, J.A. The function of the respiratory supercomplexes: The plasticity model. BBA-Bioenergetics 2014, 1837, 444-450. [CrossRef]

26. Heo, S.-J.; Jeon, Y.-J. Radical scavenging capacity and cytoprotective effect of enzymatic digests of Ishige okamurae. J. Appl. Phycol. 2008, 20, 1087-1095. [CrossRef]

27. Ellulu, M.S.; Patimah, I.; Khaza'ai, H.; Rahmat, A.; Abed, Y. Obesity and inflammation: The linking mechanism and the complications. Arch. Med. Sci. AMS 2017, 13, 851. [CrossRef]

28. Holguin, F.; Fitzpatrick, A. Obesity, asthma, and oxidative stress. J. Appl. Physiol. 2009, 108, 754-759. [CrossRef]

29. Lee, H.; Lee, Y.J.; Choi, H.; Ko, E.H.; Kim, J.-W. Reactive oxygen species facilitate adipocyte differentiation by accelerating mitotic clonal expansion. J. Biol. Chem. 2009, 284, 10601-10609. [CrossRef] [PubMed]

30. Fajas, L. Adipogenesis: A cross-talk between cell proliferation and cell differentiation. Ann. Med. 2003, 35, 79-85. [CrossRef] [PubMed]

31. Cha, S.-Y.; Cheon, Y.-P. Suppressive Effects of an Ishige okamurae extract on 3T3-L1 Preadipocyte Differentiation. Dev. Reprod. 2013, 17, 451. [CrossRef] [PubMed]

32. Polvani, S.; Tarocchi, M.; Tempesti, S.; Bencini, L.; Galli, A. Peroxisome proliferator activated receptors at the crossroad of obesity, diabetes, and pancreatic cancer. World J. Gastroenterol. 2016, 22, 2441. [CrossRef] [PubMed]

33. Tontonoz, P.; Hu, E.; Spiegelman, B.M. Stimulation of adipogenesis in fibroblasts by PPAR $\gamma 2$, a lipid-activated transcription factor. Cell 1994, 79, 1147-1156. [CrossRef]

34. Rosen, E.D.; Sarraf, P.; Troy, A.E.; Bradwin, G.; Moore, K.; Milstone, D.S.; Spiegelman, B.M.; Mortensen, R.M. $\operatorname{PPAR} \gamma$ is required for the differentiation of adipose tissue in vivo and in vitro. Mol. Cell 1999, 4, 611-617. [CrossRef]

35. Hong, S.J.; Lee, J.-H.; Kim, E.J.; Yang, H.J.; Park, J.-S.; Hong, S.-K. Anti-obesity and anti-diabetic effect of neoagarooligosaccharides on high-fat diet-induced obesity in mice. Mar. Drugs 2017, 15, 90. [CrossRef]

36. Seo, Y.-J.; Lee, K.; Song, J.-H.; Chei, S.; Lee, B.-Y. Ishige okamurae extract suppresses obesity and hepatic steatosis in high fat diet-induced obese mice. Nutrients 2018, 10, 1802. [CrossRef]

37. Yamauchi, T.; Kamon, J.; Minokoshi, Y.A.; Ito, Y.; Waki, H.; Uchida, S.; Yamashita, S.; Noda, M.; Kita, S.; Ueki, K. Adiponectin stimulates glucose utilization and fatty-acid oxidation by activating AMP-activated protein kinase. Nat. Med. 2002, 8, 1288. [CrossRef]

38. Watanabe, M.; Houten, S.M.; Mataki, C.; Christoffolete, M.A.; Kim, B.W.; Sato, H.; Messaddeq, N.; Harney, J.W.; Ezaki, O.; Kodama, T. Bile acids induce energy expenditure by promoting intracellular thyroid hormone activation. Nature 2006, 439, 484. [CrossRef]

39. Uno, K.; Katagiri, H.; Yamada, T.; Ishigaki, Y.; Ogihara, T.; Imai, J.; Hasegawa, Y.; Gao, J.; Kaneko, K.; Iwasaki, H. Neuronal pathway from the liver modulates energy expenditure and systemic insulin sensitivity. Science 2006, 312, 1656-1659. [CrossRef]

40. Matsuoka, T.-A.; Kajimoto, Y.; Watada, H.; Kaneto, H.; Kishimoto, M.; Umayahara, Y.; Fujitani, Y.; Kamada, T.; Kawamori, R.; Yamasaki, Y. Glycation-dependent, reactive oxygen species-mediated suppression of the insulin gene promoter activity in HIT cells. J. Clin. Investig. 1997, 99, 144-150. [CrossRef] [PubMed] 
41. Rudich, A.; Tirosh, A.; Potashnik, R.; Hemi, R.; Kanety, H.; Bashan, N. Prolonged oxidative stress impairs insulin-induced GLUT4 translocation in 3T3-L1 adipocytes. Diabetes 1998, 47, 1562-1569. [CrossRef] [PubMed]

42. Kodama, H.; Fujita, M.; Yamazaki, M.; Yamaguchi, I. The possible role of age-related increase in the plasma glucagon/insulin ratio in the enhanced hepatic gluco neogenesis and hyperglycemia in genetically diabetic (C57BL/KsJ-db/db) mice. JPN J. Pharmacol. 1994, 66, 281-287. [CrossRef]

43. Haffner, S.M.; Miettinen, H.; Stern, M.P. The homeostasis model in the San Antonio heart study. Diabetes Care 1997, 20, 1087-1092. [CrossRef]

44. Tahara, Y.; Shima, K. Kinetics of HbA1c, glycated albumin, and fructosamine and analysis of their weight functions against preceding plasma glucose level. Diabetes Care 1995, 18, 440-447. [CrossRef] [PubMed]

45. Singh, I.P.; Bharate, S.B. Phloroglucinol compounds of natural origin. Nat. Prod. Rep. 2006, 23, 558-591. [CrossRef]

46. Handique, J.; Baruah, J. Polyphenolic compounds: An overview. React. Funct. Polym. 2002, 52, $163-188$. [CrossRef]

47. Mayer, A.M.; Hamann, M.T. Marine pharmacology in 2001-2002: Marine compounds with anthelmintic, antibacterial, anticoagulant, antidiabetic, antifungal, anti-inflammatory, antimalarial, antiplatelet, antiprotozoal, antituberculosis, and antiviral activities; affecting the cardiovascular, immune and nervous systems and other miscellaneous mechanisms of action. Comp. Biochem. Physiol. C: Toxicol. Pharmacol. 2005, 140, 265-286.

48. Kong, C.-S.; Kim, J.-A.; Yoon, N.-Y.; Kim, S.-K. Induction of apoptosis by phloroglucinol derivative from Ecklonia cava in MCF-7 human breast cancer cells. Food Chem. Toxicol. 2009, 47, 1653-1658. [CrossRef] [PubMed]

49. Yoon, N.Y.; Lee, S.-H.; Kim, S.-K. Phlorotannins from Ishige okamurae and their acetyl-and butyrylcholinesterase inhibitory effects. J. Funct. Foods 2009, 1, 331-335. [CrossRef]

50. Kim, H.-H.; Kim, H.-S.; Ko, J.-Y.; Kim, C.-Y.; Lee, J.-H.; Jeon, Y.-J. A single-step isolation of useful antioxidant compounds from Ishige okamurae by using centrifugal partition chromatography. Fish Aquat. Sci. 2016, 19, 22. [CrossRef]

51. Ryu, B.; Jiang, Y.; Kim, H.-S.; Hyun, J.-M.; Lim, S.-B.; Li, Y.; Jeon, Y.-J. Ishophloroglucin A, a novel phlorotannin for standardizing the anti- $\alpha$-glucosidase activity of Ishige okamurae. Mar. Drugs 2018, 16, 436. [CrossRef]

52. Zou, Y.; Qian, Z.-J.; Li, Y.; Kim, M.-M.; Lee, S.-H.; Kim, S.-K. Antioxidant effects of phlorotannins isolated from Ishige okamurae in free radical mediated oxidative systems. J. Agric. Food Chem. 2008, 56, 7001-7009. [CrossRef] [PubMed]

53. Heo, S.-J.; Jeon, Y.-J. Evaluation of diphlorethohydroxycarmalol isolated from Ishige okamurae for radical scavenging activity and its protective effect against H2O2-induced cell damage. Process Biochem. 2009, 44, 412-418. [CrossRef]

54. Kumar, S.; Hosokawa, M.; Miyashita, K. Fucoxanthin: A marine carotenoid exerting anti-cancer effects by affecting multiple mechanisms. Mar. Drugs 2013, 11, 5130-5147. [CrossRef]

55. Liu, C.-L.; Liang, A.-L.; Hu, M.-L. Protective effects of fucoxanthin against ferric nitrilotriacetate-induced oxidative stress in murine hepatic BNL CL. 2 cells. Toxicol. In Vitro 2011, 25, 1314-1319. [CrossRef]

56. Maeda, H.; Hosokawa, M.; Sashima, T.; Funayama, K.; Miyashita, K. Fucoxanthin from edible seaweed, Undaria pinnatifida, shows antiobesity effect through UCP1 expression in white adipose tissues. Biochem. Biophys. Res. Commun. 2005, 332, 392-397. [CrossRef] [PubMed]

57. Maeda, H.; Hosokawa, M.; Sashima, T.; Miyashita, K. Dietary combination of fucoxanthin and fish oil attenuates the weight gain of white adipose tissue and decreases blood glucose in obese/diabetic KK-Ay mice. J. Agric. Food Chem. 2007, 55, 7701-7706. [CrossRef] [PubMed]

58. Kang, M.-C.; Lee, S.-H.; Lee, W.-W.; Kang, N.; Kim, E.-A.; Kim, S.Y.; Lee, D.H.; Kim, D.; Jeon, Y.-J. Protective effect of fucoxanthin isolated from Ishige okamurae against high-glucose induced oxidative stress in human umbilical vein endothelial cells and zebrafish model. J. Funct. Foods 2014, 11, 304-312. [CrossRef]

59. Payne, V.A.; Au, W.-S.; Lowe, C.E.; Rahman, S.M.; Friedman, J.E.; O’Rahilly, S.; Rochford, J.J. C/EBP transcription factors regulate SREBP1c gene expression during adipogenesis. Biochem. J. 2010, 425, 215-224. [CrossRef] 
60. Choi, H.S.; Jeon, H.J.; Lee, O.H.; Lee, B.Y. Dieckol, a major phlorotannin in Ecklonia cava, suppresses lipid accumulation in the adipocytes of high-fat diet-fed zebrafish and mice: Inhibition of early adipogenesis via cell-cycle arrest and AMPK $\alpha$ activation. Mol. Nutr. Food Res. 2015, 59, 1458-1471. [CrossRef]

61. Chan, C.Y.; Wei, L.; Castro-Muñozledo, F.; Koo, W.L. (-)-Epigallocatechin-3-gallate blocks 3T3-L1 adipose conversion by inhibition of cell proliferation and suppression of adipose phenotype expression. Life Sci. 2011, 89, 779-785. [CrossRef]

62. Chang, C.-C.; Lin, K.-Y.; Peng, K.-Y.; Day, Y.-J.; Hung, L.-M. Resveratrol exerts anti-obesity effects in high-fat diet obese mice and displays differential dosage effects on cytotoxicity, differentiation, and lipolysis in 3T3-L1 cells. Endocr. J. 2016, 63, 169-178. [CrossRef]

63. Kang, M.-C.; Ding, Y.; Kim, H.-S.; Jeon, Y.-J.; Lee, S.-H. Inhibition of Adipogenesis by Diphlorethohydroxycarmalol (DPHC) through AMPK activation in adipocytes. Mar. Drugs 2019, 17, 44. [CrossRef] [PubMed]

64. Park, M.H.; Jeon, Y.J.; Kim, H.J.; Han, J.S. Effect of Diphlorethohydroxycarmalol isolated from ishige okamurae on apoptosis in 3 t3-L1 preadipocytes. Phytother. Res. 2013, 27, 931-936. [CrossRef] [PubMed]

65. Gray, G.M. Carbohydrate digestion and absorption: Role of the small intestine. N. Engl. J. Med. 1975, 292, 1225-1230. [CrossRef]

66. Dong, H.-Q.; Li, M.; Zhu, F.; Liu, F.-L.; Huang, J.-B. Inhibitory potential of trilobatin from Lithocarpus polystachyus Rehd against $\alpha$-glucosidase and $\alpha$-amylase linked to type 2 diabetes. Food Chem. 2012, 130, 261-266. [CrossRef]

67. Collado-González, J.; Grosso, C.; Valentão, P.; Andrade, P.B.; Ferreres, F.; Durand, T.; Guy, A.; Galano, J.-M.; Torrecillas, A.; Gil-Izquierdo, Á. Inhibition of $\alpha$-glucosidase and $\alpha$-amylase by Spanish extra virgin olive oils: The involvement of bioactive compounds other than oleuropein and hydroxytyrosol. Food Chem. 2017, 235, 298-307. [CrossRef]

68. Heo, S.-J.; Hwang, J.-Y.; Choi, J.-I.; Han, J.-S.; Kim, H.-J.; Jeon, Y.-J. Diphlorethohydroxycarmalol isolated from Ishige okamurae, a brown algae, a potent $\alpha$-glucosidase and $\alpha$-amylase inhibitor, alleviates postprandial hyperglycemia in diabetic mice. Eur. J. Pharmacol. 2009, 615, 252-256. [CrossRef] [PubMed]

69. Lee, S.-H.; Choi, J.-I.; Heo, S.-J.; Park, M.-H.; Park, P.-J.; Jeon, B.-T.; Kim, S.-K.; Han, J.-S.; Jeon, Y.-J. Diphlorethohydroxycarmalol isolated from Pae (Ishige okamurae) protects high glucose-induced damage in RINm5F pancreatic $\beta$ cells via its antioxidant effects. Food Sci. Biotechnol. 2012, 21, 239-246. [CrossRef]

70. Stumvoll, M.; Goldstein, B.J.; van Haeften, T.W. Type 2 diabetes: Principles of pathogenesis and therapy. Lancet 2005, 365, 1333-1346. [CrossRef]

71. Roberfroid, M.B. Concepts and strategy of functional food science: The European perspective. Am. J. Clin. Nutr. 2000, 71, 1660S-1664S. [CrossRef]

72. Barrow, C.; Shahidi, F. Marine Nutraceuticals and Functional Foods; CRC Press: Boca Raton, FL, USA, 2007.

73. Kim, S.-K.; Mendis, E. Bioactive compounds from marine processing byproducts-A review. Food Res. Int. 2006, 39, 383-393. [CrossRef]

74. Zou, Y.; Li, Y.; Kim, M.-M.; Lee, S.-H.; Kim, S.-K. Ishigoside, a new glyceroglycolipid isolated from the brown alga Ishige okamurae. Biotechnol. Bioprocess Eng. 2009, 14, 20-26. [CrossRef]

75. Bae, M.J.; Karadeniz, F.; Ahn, B.-N.; Kong, C.-S. Evaluation of effective MMP inhibitors from eight different brown algae in human fibrosarcoma HT1080 cells. PNF 2015, 20, 153. [CrossRef] [PubMed]

76. Kim, M.M.; Rajapakse, N.; Kim, S.K. Anti-inflammatory effect of Ishige okamurae ethanolic extract via inhibition of NF-kB transcription factor in RAW 264.7 cells. Phytother. Res. 2009, 23, 628-634. [CrossRef] [PubMed]

77. Lee, W.; Kang, N.; Kim, E.-A.; Yang, H.-W.; Oh, J.-Y.; Fernando, I.P.S.; Kim, K.-N.; Ahn, G.; Jeon, Y.-J. Radioprotective effects of a polysaccharide purified from Lactobacillus plantarum-fermented Ishige okamurae against oxidative stress caused by gamma ray-irradiation in zebrafish in vivo model. J. Funct. Foods 2017, 28, 83-89. [CrossRef]

78. Heo, S.-J.; Hwang, J.-Y.; Choi, J.-I.; Lee, S.-H.; Park, P.-J.; Kang, D.-H.; Oh, C.; Kim, D.-W.; Han, J.-S.; Jeon, Y.-J. Protective effect of diphlorethohydroxycarmalol isolated from Ishige okamurae against high glucose-induced-oxidative stress in human umbilical vein endothelial cells. Food Chem. Toxicol. 2010, 48, 1448-1454. [CrossRef] 
79. Heo, S.-J.; Cha, S.-H.; Kim, K.-N.; Lee, S.-H.; Ahn, G.; Kang, D.-H.; Oh, C.; Choi, Y.-U.; Affan, A.; Kim, D. Neuroprotective effect of phlorotannin isolated from Ishige okamurae against $\mathrm{H} 2 \mathrm{O}$ 2-induced oxidative stress in murine hippocampal neuronal cells, HT22. Appl. Biochem. Biotechnol. 2012, 166, 1520-1532. [CrossRef]

80. Ahn, M.J.; Yoon, K.D.; Kim, C.; Kim, J.; Shin, C.G.; Kim, J. Inhibitory activity on HIV-1 reverse transcriptase and integrase of a carmalol derivative from a brown Alga, Ishige okamurae. Phytother. Res. 2006, 20, 711-713. [CrossRef]

81. Kim, K.-N.; Heo, S.-J.; Yoon, W.-J.; Kang, S.-M.; Ahn, G.; Yi, T.-H.; Jeon, Y.-J. Fucoxanthin inhibits the inflammatory response by suppressing the activation of NF-KB and MAPKs in lipopolysaccharide-induced RAW 264.7 macrophages. Eur. J. Pharmacol. 2010, 649, 369-375. [CrossRef] [PubMed]

82. Milatovic, D.; Dettbarn, W.-D. Modification of acetylcholinesterase during adaptation to chronic, subacute paraoxon application in rat. Toxicol. Appl. Pharmacol. 1996, 136, 20-28. [CrossRef]

83. Schetinger, M.R.; Porto, N.M.; Moretto, M.B.; Morsch, V.M.; da Rocha, J.B.T.; Vieira, V.; Moro, F.; Neis, R.T.; Bittencourt, S.; Bonacorso, H.G. New benzodiazepines alter acetylcholinesterase and ATPDase activities. Neurochem. Res. 2000, 25, 949-955. [CrossRef]

84. Greig, N.H.; Utsuki, T.; Yu, Q.-S.; Zhu, X.; Holloway, H.W.; Perry, T.; Lee, B.; Ingram, D.K.; Lahiri, D.K. A new therapeutic target in Alzheimer's disease treatment: Attention to butyrylcholinesterase. Curr. Med. Res. Opin. 2001, 17, 159-165. [CrossRef] [PubMed]

85. Hosokawa, M. Fucoxanthin as a bioactive and nutritionally beneficial marine carotenoid. Carotenoid Sci. 2006, 10, 15-28.

86. Pahl, H.L. Activators and target genes of Rel/NF- kB transcription factors. Oncogene 1999, 18, 6853. [CrossRef] [PubMed]

87. Uto, T.; Fujii, M.; Hou, D.-X. 6-(Methylsulfinyl) hexyl isothiocyanate suppresses inducible nitric oxide synthase expression through the inhibition of Janus kinase 2-mediated JNK pathway in lipopolysaccharide-activated murine macrophages. Biochem. Pharmacol. 2005, 70, 1211-1221. [CrossRef] [PubMed]

88. Balkwill, F.; Coussens, L.M. Cancer: An inflammatory link. Nature 2004, 431, 405. [CrossRef] [PubMed] 